\title{
Outcome of children referred with heart murmurs referred from general practice to a paediatrician with expertise in cardiology - ERRATUM
}

\author{
Abha Khushu, Anthony W. Kelsall, Juliet A. Usher-Smith \\ Keywords: Paediatrics; heart murmur; referral; general practice; erratum \\ doi:10.1017/S104795111400095X, Published by Cambridge University Press, 9 June 2014.
}

First published online: 3 July 2014

The Publisher apologises for the error in the title of this article shown above. It has now been corrected online to the following:

Outcome of children with heart murmurs referred from general practice to a paediatrician with expertise in cardiology

\section{Reference}

1. Khushu A, Kelsall AW, Usher-Smith JA. Outcome of children with heart murmurs referred from general practice to a paediatrician with expertise in cardiology. Cardiology in the Young. Published by Cambridge University Press, 9 June 2014. doi:10.1017/S104795111400095X. 